\title{
Labyrint(h)ing with the forest and more to come
}

....Following a trail that eventually lead through the labyrinths including the impasse, detours, traps, blind alleys ....

- other turns and options again and again is about how to go further than the former - not one solution - not one strait line guiding the labyrinth.....

Doing....walking.... thinking....sensing....hearing and smelling bodily when our bodyings are transversal, collective before they are individual, more-than in/with a different forest universe- a labyrinth in togetherness with other bodyings - a new territory and not to come.

I/we have been here before, in the present, oriented with real experimentation -and 'new' connections and any 'we' transformations is already composing the spaces of these troubled collaborations between the more-than in the darkness. I assume I have been here before not knowing this specific territory.

How else can one write but of those things which one does not know, or knows badly? It is precisely there that I/we imagine having something to say. We write only at the frontiers of our knowledge, at the border, which separates our knowledge from our ignorance and transforms the one into the other. How can we continue with the differential of the more-than-human that composes us, with the kinships that make us more-than ourselves, engaging in the network of power/knowledge durations that (de)compose us.... (Manning, unpublished, 2017). 


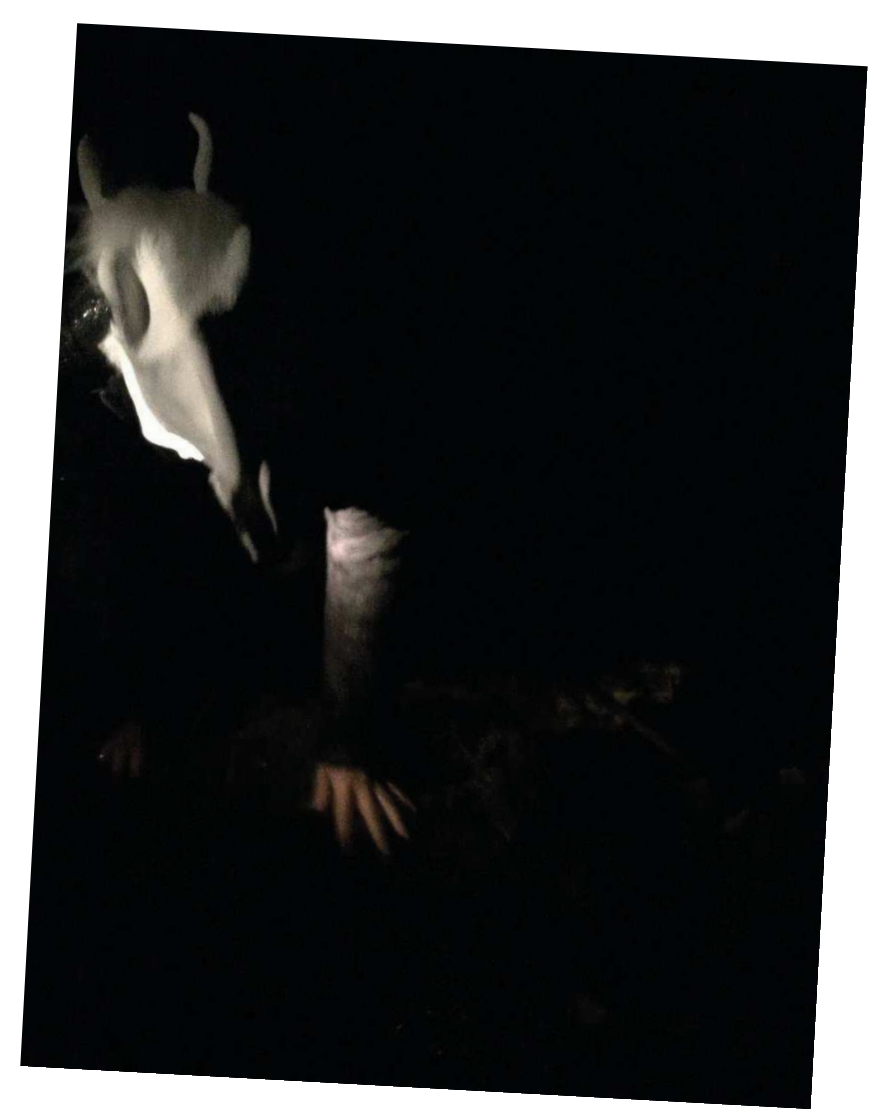

Only in this manner are we resolved to write. To satisfy ignorance is to put off writing until tomorrow - or rather, to make it impossible. Perhaps writing has a relation to silence altogether more threating than it is supposed to entertain with death (Deleuze \& Guattari, 1994: xxi).

....the labyrinth is a slow moving machine. It is structurally incapable of changing at the speed of the thought that moves through it. ...bodying and how the body becomes might also solidify them from the outside into different bodies - of the horse body, the trans body, the mother body.... the potentials for a body to shift, to alter the conditions of life-living, life in the register and shifts of the more-than (Manning, 2017)....

.... a rhizome is different from roots and radicles.....bulbs and tubers are rhizomes..... rhizomorphic.... not individual 'radicles' connecting.... multiplicities connecting to other multiplicities.... The forest bodying is also a question of moving sideways, of attuning to the sideways movements already there, following their line of flight. .... darkness connecting to other 
darkness.... Labyrinthine

walking and being labyrin(t)hings -potentials ....

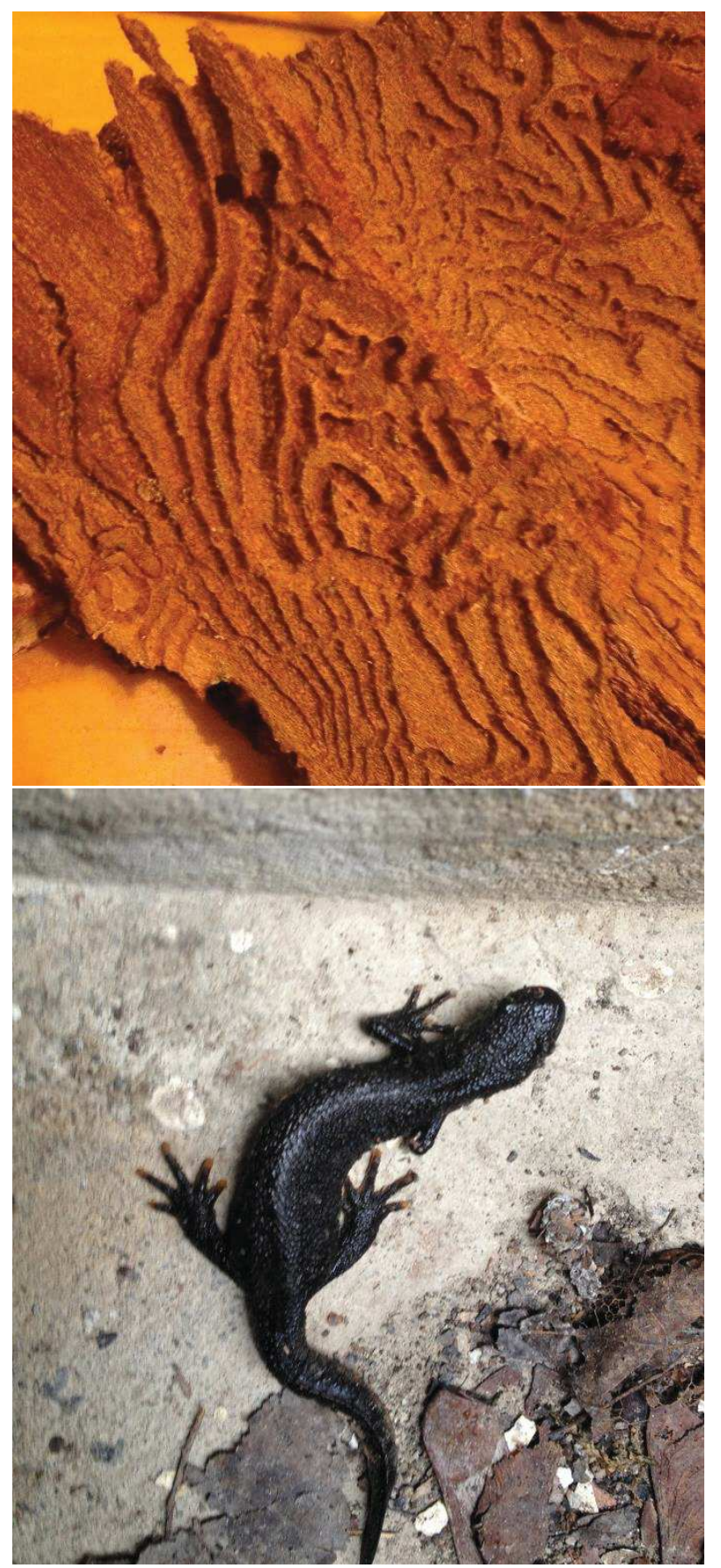

... multiplicities can become symbolic in order to explore the entanglements of one multiplicity to another and not limited to only two multiplies...... 
A multiplicity is continually transforming itself into a string of other multiplicities according to its thresholds and doors. ....the multiplicity toward which it leans, stretching to the breaking point, is the continuation of another multiplicity that works it and strains it from the inside. In fact the self is only a threshold, a door, a becoming between two multiplicities... (Deleuze \& Guattari, 1987, p. 275).

a labyrinth of creation and transformation where the labyrinth is what leads to becoming.... is that of the labyrinth itself $(:)$ (Deleuze 1983/, p. 188).

I wander in a labyrinth of sensing - my organs - my bodying ...and organizes as if becoming horse ..... is in the multiplicities...

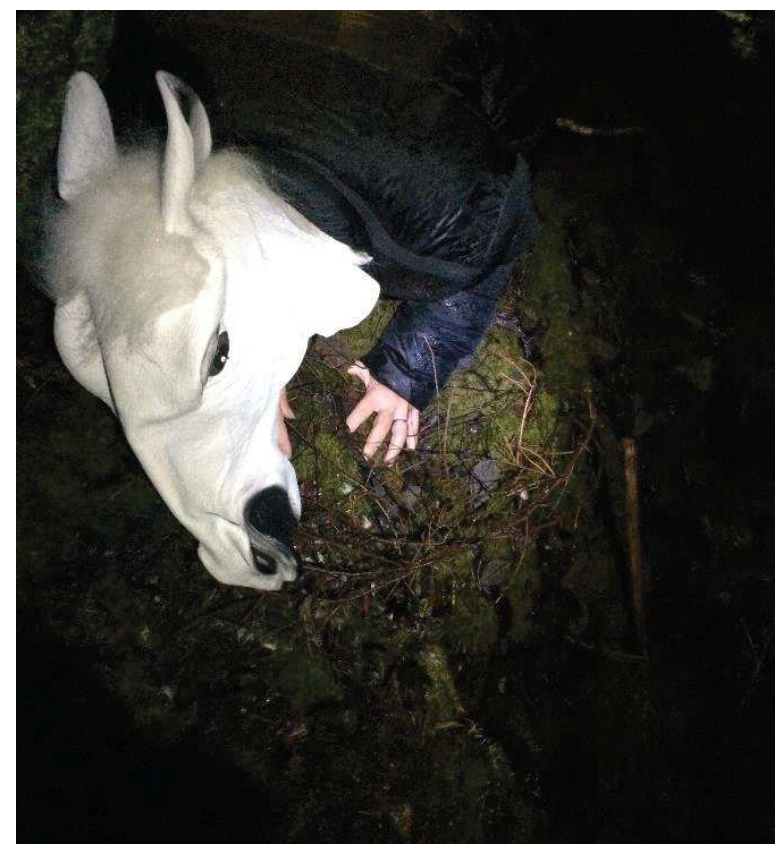




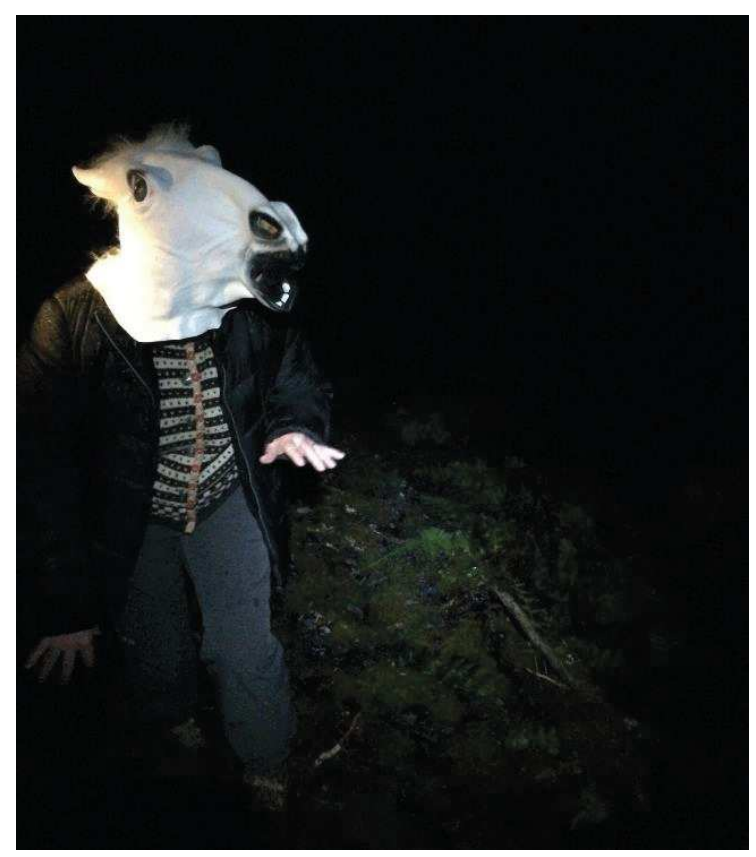

The treads of the labyrinth is a link to the event to come....the labyrinth of the event.

Life itself is not an escape - not a lost way, which is, which was, which will be (Deleuze, 1983, p. 188)

...affirming the event is affirming becoming...

Dionysus not only asks Ariadne to hear but to affirm affirmation.... 'you have little ears, you have my ears: put a shrewd word there'

The ear is labyrinthine, the ear is the labyrinth of becoming or the maze of affirmation.

The Labyrinth is what leads us to being, the only being is that of becoming, the only being is that of the labyrinth itself.

But Ariadne has Dionysus ears: affirmation must itself be affirmed so that it can be the affirmation of being. Ariadne puts shrewd word into Dionysian' ear.

That is to say: having Dionysian affirmation, she makes the object of a second affirmation heard by Dionysus (Deleuze, 1986, p. 178) 


\section{a different forest universities of becoming}

Hapticality, the touch of the ground, the interiority of sentiment, and the sensation that what is to come is here. Hapticality, the possibility to bodily affirm that distributions is not regulated, at least not successfully, by politics, a people, a piece of land, a symbol. Senses touches. Thrown together in labyrinths touching each other we were not denied all sentiment, not denied all the things that were supposed to produce sentiment, family, nation, language, religion, place, home. Though forced to touch and be touched to sense and become sensed in that forest space of darkness becoming (for) each other.

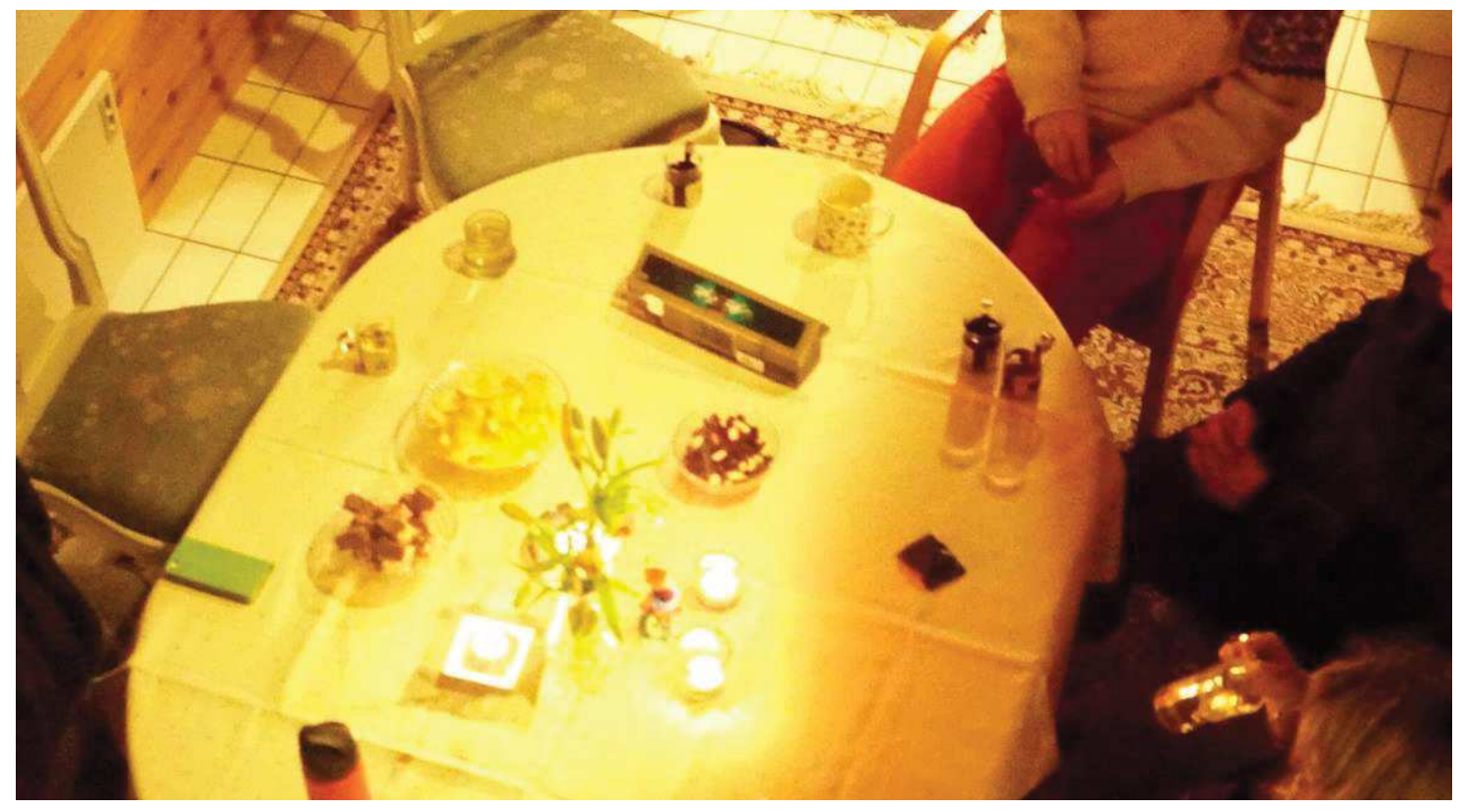

'Between power and knowledge there is a difference in nature or a heterogeneity; but there is also mutual presupposition and capture; and there is ultimately a primacy of the one over the other. First of all there is a difference in nature, since power does not pass through forms, but only through forces. Knowledge concerns formed matters (substances) and formalized functions, divided up segment by segment according to the two great formal conditions of seeing and speaking, light and language: it is therefore stratified, archivized, and endowed with a relatively rigid segmentarity. Power, on the other hand, is diagrammatic: it mobilizes non-stratified matter and functions, and unfolds with a very flexible segmentarity. In fact, it passes not so much through forms as through particular points which on each occasion 
mark the application of a force, the action or reaction of a force in relation to others, that is to say an affect like 'a state of power that is always local and unstable' (Deleuze, 1988, p. 73)".

As well as a multitude to come...

\section{References}

Deleuze, G. (1986). Nietzsche and philosophy (H. Tomlinson, Trans. 2002 ed.). London: Continuum (Originally published as Nietzsche et la philosophie, 1962).

Deleuze, G. (1988). Spinoza: Practical Philosophy. (Robert Hurley, Trans) San Fransisco: City Lights Books.

Deleuze, G. (1983/1989). Cinema 2: The Time Image. Trans. Hugh Tomlinson and Robert Galeta. Minneapolis: University of Minnesota Press.

Deleuze, G. \& Guattari, F. (1987). A thousand plateaus: Capitalism and schizophrenia (B. Massumi, Trans. 2004 ed.). London: Continuum (Originally published as Milles Plateaux, volume 2 Capitalisme et Schizophénie, 1980).

Deleuze, G. \& Guattari, F. (1994). What is philosophy? (G. Burchell \& H. Tomlinson, Trans.). London: Verso (Originally published as Qu'est-ce que la philosophie?, 1991).

Manning, E. (unpublished). (2017). Me Lo Dijo Un Pajarito - Neurodiversity, Black Life and the University As We Know It. 